\title{
“O TEXTO QUE ME INSTITUIU": UM OUTRO PERFIL DE LEITOR
}

Rildo Cosson*

(D) https://orcid.org/0000-0003-2677-5149

Como citar este artigo: COSSON, R. "O texto que me instituiu": um outro perfil de leitor. Todas as Letras - Revista de Lingua e Literatura, São Paulo, v. 23, n. 1, p. 1-13, jan./abr. 2021. DOI 10.5935/1980-6914/eLETOL2113426

Submissão: maio de 2020. Aceite: agosto de 2020.

Resumo: A forma mais comum de traçar um perfil de leitor é o levantamento dos comportamentos de leitura de uma população. Neste estudo, apresenta-se a prática "O texto que me instituiu" como uma modalidade alternativa de perfil de leitor. Os dados foram coletados em uma turma de pós-graduação em Letras e tratados com o software QDA Miner para a análise de conteúdo. Os resultados revelam que essa prática é uma maneira relevante de se traçar o perfil de leitor de uma turma de alunos, podendo ser usada, desde o ensino médio, não só para o planejamento das leituras futuras, como também para a interação entre professor e alunos, sendo para ambos um ponto de partida promissor.

Palavras-chave: Perfil de leitor. História do leitor. Prática didática. Letramento literário. Leitor literário. 


\section{O PERFIL DE LEITOR COMO PRÁTICAS DE LEITURA}

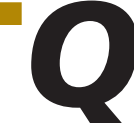

uando se fala em traçar um perfil de leitor, o modelo das pesquisas de opinião sobre as práticas dos leitores e as condições de leitura parece ser o instrumento mais adequado. A pesquisa "Retratos da leitura do Brasil", com abrangência nacional, é, certamente, o exemplo mais conhecido entre nós desse tipo de perfil de leitor. Realizada periodicamente, a pesquisa já está em sua quarta edição (FAILLA, 2016) e encontra ampla divulgação na imprensa e respaldo em textos acadêmicos que utilizam seus dados como base para aprofundá-los, questioná-los ou realizar outros estudos (FARIAS, 2018; AMARAL, 2018; PAGNAN, 2018). Há também perfis de leitor que são voltados para um determinado nivel de ensino ou curso, como é o caso das pesquisas feitas com estudantes de nivel superior em Portugal (YUBERO, 2014) e alunos das licenciaturas de Letras e Pedagogia de três grandes universidades brasileiras (GIROTTO; FRANCO, 2017), assim como há perfis de leitor bem específicos, como os alunos de uma determinada escola (CHUCRE, 2018).

Esse tipo de perfil de leitor ainda se faz presente, como complemento ou suplemento, em outros estudos. É o caso dos testes de conhecimento, seja em âmbito internacional ou nacional, que introduzem, antes dos testes, questões sobre o perfil socioeconômico e o perfil de leitor do aluno. O teste de leitura Pisa, por exemplo, é acompanhado de um questionário de contexto que contém toda uma seção dedicada às atividades de leitura do aluno, como o tempo que passa a ler por prazer, frequência de leitura e valor da leitura (OCDE, 2009).

Independentemente do universo de sua aplicação ou do objetivo para que foi elaborado, o perfil de leitor obtido por meio desse tipo de pesquisa segue basicamente o mesmo roteiro. Trata-se de um questionário com alternativas fechadas para identificar as características mais relevantes de práticas de leitura daquele conjunto de leitores. É isso que se pode observar no documento "Metodologia comum para examinar e medir o comportamento leitor. O encontro com o digital", do Centro Regional para o Fomento do Livro na América e o Caribe (MONAK, 2015), que orienta o levantamento de características como frequência e intensidade da leitura, hábitos de leitura, motivos para ler e não ler, a leitura na infância, o modo de leitura de livros, jornais e revistas, entre outros aspectos.

Não é difícil perceber que o documento, já a partir de seu título, reconhece que se trata de traçar o comportamento do leitor, ou seja, aquelas práticas que são socialmente identificadas como próprias de um leitor. Daí a limitação que os indicadores usados podem trazer para o perfil de leitor, até porque, como consta muito bem na parte conceitual do documento, a leitura é um fenômeno complexo, que não se deixa facilmente apreender.

Em nossa perspectiva, para além de questões limitadoras como definir o leitor como aquele que leu um livro em determinado período de tempo, tal como acontece na pesquisa "Retratos da leitura no Brasil", há, ainda, nesses levantamentos, embora não de maneira explícita, uma identificação última do leitor ideal com o leitor literário ou, mais propriamente, com o leitor do texto impresso literário. É o que se observa, por exemplo, quando se correlaciona a leitura de livros a atividades de lazer. A despeito disso, não há nesses questionários, por sua amplitude e generalidade, e também por não ser este seu objetivo, um delineamento adequado do leitor literário. 
Todavia, se o perfil de leitor traçado por meio desses questionários gerais tende a ser muito amplo e, por isso, pouco específico quanto ao leitor literário, há alternativas que buscam delinear não as práticas de leitura, mas o leitor literário em si mesmo. Essa é a proposta de David Miall e Don Kuiken (1995), que elaboraram um questionário para medir a relação do leitor com os textos literários. Apoiados em pesquisas anteriores e adotando a análise fatorial como método, os autores construíram um questionário, na forma de escala de Likert, de 68 itens agrupados em sete fatores que acreditam cobrir as diversas características de um leitor literário ou da interação do leitor com textos literários: revelação (insight), empatia, percepção da imagética (imagery vividness), imersão (leisure escape), preocupação com o autor, leitura do enredo e rejeição do aparato crítico. A análise feita pelos autores revela, ainda, que esses sete fatores podem ser reagrupados em dois grandes fatores: experienciação, que abarca revelação, empatia, percepção da imagética e imersão; e compreensão literal, que integra a leitura do enredo e a rejeição do aparato crítico, sendo que a preocupação com o autor se divide entre eles.

O detalhamento operado pelos itens, a abrangência dos fatores e o suporte metodológico consistente fazem do Questionário de Interação Literária (Literary Response Questionnaire - LQR) de Miall e Kuiken uma contribuição importante para a avaliação do leitor literário. Tanto que a proposta dos autores foi adotada por outros pesquisadores e aplicada com ou sem ajustes para diversos públicos em diferentes lugares, a exemplo de Wong (1997) em Singapura, Schooten et al. (2001) nos Países Baixos e Masoomi e Zargar (2017) no Irã. No entanto, até por seu rigor metodológico e conceitual, o LQR não é uma medida fácil de ser manejada, sobretudo quando o propósito é tão somente delinear o perfil de leitor de uma turma para seleção de textos e direcionamento de atividades de leitura. É para atender a esse objetivo comum a todos os professores perante uma nova turma de alunos que apresentaremos a seguir uma forma alternativa à aplicação de questionários para traçar um perfil de leitor que denominamos "O texto que me instituiu"1.

\section{UM PERFIL ALTERNATIVO: “O TEXTO QUE ME INSTITUIU”}

A atividade "O texto que me instituiu" é uma prática a ser desenvolvida no primeiro dia de aula ou subsequente. Trata-se da escrita de um texto de cunho memorialístico que apresenta o impacto de textos literários na história do leitor. Apesar de haver vários estudos sobre memória do leitor escolar que podem ser usados como inspiração e fundamento para a prática (DRESCH et al., 2011; ASSOLINI, 2011; ALMEIDA, 2019), o suporte conceitual que adotamos vem do paradigma do letramento literário, no qual se defende que a leitura dos textos literários nos constitui como sujeitos na linguagem, ou seja, os textos literários alimentam o nosso imaginário e nos dão palavras com as quais construímos simbolicamente a nós e ao mundo. Temos, assim, um corpo linguagem em paralelo ao corpo físico que é constituído pelos textos que lemos e que se expande e se fortalece a cada novo texto lido (COSSON, 2006).

Metodologicamente, a prática consiste em uma sequência de leitura e escrita de textos em sala de aula, usualmente dividida em três atividades. A primeira é

\footnotetext{
Agradecemos ao prof. Antônio Adailton Silva, doutor pela Universidade Federal do Tocantins (UFT), que sugeriu o nome e o arredondamento dessa prática quando compartilhávamos nossas experiências de ensino de literatura.
} 
a leitura de um texto que tematize a memória do leitor ou um texto que trate da leitura literária em qualquer circunstância, preferencialmente biográfico ou autobiográfico. Por meio de um texto com essa temática, o professor introduz, explicitamente ou não, a concepção de que somos atravessados pelos textos que lemos e que a literatura é o alimento principal de nosso corpo linguagem. A segunda atividade é uma discussão sobre o texto primeiro que, respeitando suas características, deve ter como eixo a transposição da experiência relatada pelo autor para a experiência do aluno sobre os textos que o marcaram durante sua formação de leitor até o presente. A terceira atividade, logo em seguida à discussão, é a produção de uma memória com o seguinte comando: "Todos nós, que somos leitores, temos um ou mais textos que foram decisivos em nossa história de leitor, que nos 'instituíram' como leitor. Exponha sua experiência em não menos que uma lauda".

O resultado da prática são textos que revelam o impacto que certas obras tiveram sobre o leitor juntamente com hábitos, influência, motivação, valores, identidade e outros dados que possibilitam a construção do perfil de leitor literário individual de cada aluno e da turma como um todo. Ao narrar o momento ou os momentos decisivos de sua história de leitor, o aluno indica, por exemplo, a partir de que momento de sua vida, infância, adolescência ou fase adulta, o leitor se identifica como tal. Ao localizar os textos que permanecem na memória como fundamentais para sua formação, ele mostra a preferência por um determinado modo textual, se narrativa, poesia ou ambos. Ao nomear as obras, o aluno permite que se localizem estatuto, gênero, nacionalidade e endereçamento desses textos. Ao dizer como chegou a essas obras, ele indica tanto o modo de acesso quanto quais influências foram decisivas em sua história de leitor. Ao destacar um ou mais textos que foram decisivos em sua história de leitor, o aluno revela o impacto e o modo como interage com a literatura.

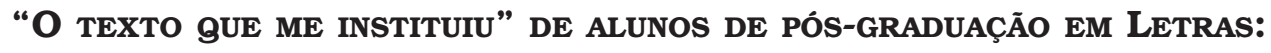 UM EXEMPLO}

Temos utilizado a prática de "O texto que me instituiu" na abertura de cursos para professores e para alunos de pós-graduação e graduação com variações de turma para turma. Acreditamos que também pode ser usada com alunos do ensino médio, sem grandes alterações. Lidos com atenção, os textos obtidos permitem que se trace um perfil de leitor dos alunos e da turma quase que intuitivamente. Porém, quando os dados são tratados sistematicamente, é possivel visualizar de maneira mais clara e segura os diversos aspectos desses perfis. Além disso, eles podem ser compartilhados com os alunos e contextualizar as escolhas que orientam as indicações de leitura e o planejamento das demais atividades do curso.

Como o número de textos é relativamente pequeno, esse tratamento dos dados pode ser feito manualmente e com os recursos que o professor conseguir dispor para apresentá-los graficamente, mas também podem ser usados instrumentos mais sofisticados, que hoje são gratuitamente disponibilizados na internet. Para dar um exemplo concreto, vamos apresentar os dados do perfil de leitor de uma turma de alunos de pós-graduação em Letras, usando para o tratamento dos textos o software QDA Miner, que oferece uma categorização sistemática e eficiente do conteúdo dos textos. 
Nessa turma específica, usamos como material de leitura textos "inusitados" oração do Pai Nosso escrita em língua wakhi, um quipo incaico, um resumo de artigo científico sobre teoria quântica, o soneto "Encomióstico" -, que desafiavam a capacidade de leitura dos alunos. Ao final dessa leitura guiada, realizamos uma conversa sobre leitura literária e memória de leitor que assumiu a forma de motivação e preparação para a produção textual. A escrita do texto de memória foi realizada como atividade extraclasse e encaminhada por e-mail para o professor.

Ainda que a leitura de um texto autobiográfico seja o procedimento mais usual na prática "O texto que me instituiu", a leitura da série de textos e a desautomatização gerada por ela mostraram que a alteração feita não impactou negativamente a produção do texto de memória, certamente pelo grau de maturidade dos alunos. A turma era constituída por 24 alunos, mas apenas 22 produziram textos. Nesse conjunto, oito alunos eram doutorandos e 14 mestrandos. Todos se consideravam leitores, alguns já eram professores experientes e outros haviam entrado para a pós-graduação em continuidade ao seu processo formativo.

$\mathrm{Na}$ leitura dos 22 textos, considerando o objetivo de traçar um perfil de leitor, depreendemos as seguintes macrocategorias: Obra, Impacto e Comportamento Leitor. Esses marcadores macros, em parte coincidentes com as propostas de perfil de leitor referidas acima, foram detalhados em subcategorias que dão substância ao perfil específico do leitor literário. A categoria Obra, que busca dar conta das várias características dos textos lidos, é composta pelas subcategorias título, autor (nacionalidade), estatuto (entretenimento, didático, popular, canônico, religioso), endereçamento (adulto, juvenil, infantil), tipo (narrativo, poético, ambos), gênero (conto, causo, conto de fadas, saga, romance, crônica, HQ, conto infantil, clássico adaptado, cordel, outro) e época (Antiguidade, séculos XV a XVIII, século XIX, século XX, século XXI). A categoria Impacto tem como subcategorias o periodo do impacto do texto, que é quando o aluno reconhece a influência do texto na sua vida (infância, adolescência, maturidade); preferência modal (narrativa, poesia, ambos); e interação literária, calcada numa adaptação do LQR, que compreende cinco marcadores: revelação (quando o texto ilumina o leitor e seu mundo), empatia (quando o aluno se identifica ou expressa compaixão por personagens e situações do texto), elaboração formal (quando o aluno destaca a maestria do autor ou a linguagem do texto), imersão (quando o texto funciona como uma forma de se separar do mundo ao redor) e enredo (quando o leitor lê o texto para conhecer a história). A categoria Comportamento do Leitor, pressupondo que todos os alunos já possuem gosto e hábito de leitura de textos literários, descreve a influência percebida na leitura dos textos, que pode vir de um membro da família (pai, mãe, avós, tios, primos), de um professor (aqui distinguido pelo nivel de ensino: EF, EM, GRA), de amigos ou outros; e o acesso aos textos, que pode ser em casa, na casa de outra pessoa da família, na escola (sala de aula, biblioteca, sala de leitura), em biblioteca pública, livraria ou ponto de venda.

\section{ANÁlise e discussão dos RESUltados}

De grande importância para a seleção de textos porque revela parte do repertório dos pesquisados, a categoria Obra mostra que a maioria dos alunos aponta vários livros como fundamentais para a sua formação de leitor, sendo que $90 \%$ desses textos são claramente identificados com título e autor. Os autores 
mais citados são Machado de Assis, Clarice Lispector e Conceição Evaristo, o primeiro citado por quatro alunos e as duas últimas por três alunos, respectivamente, indicando um claro alinhamento com o cânone nacional tradicional ao lado do acréscimo de novos critérios de canonização, como a representação de gênero e etnia. A nacionalidade dos autores citados, como se poderia esperar, é predominantemente brasileira, mencionada por mais de $80 \%$ dos alunos, seguida de longe por autores cuja língua de origem é o inglês, que são citados por cerca de 13\%, sendo que entre esses autores estão tanto Shakespeare quanto Stephenie Meyer, autora da série Crepúsculo. Na Tabela 1, na qual agrupamos nacionalidade com língua de origem, há dois aspectos a destacar. O primeiro deles é que, apesar de os alunos apresentarem um perfil de leitor do cânone brasileiro coerente com a formação recebida nos cursos de Letras, o mesmo não acontece com a citação de autores de literatura portuguesa e africana de língua portuguesa. Aparentemente, o estudo de obras e autores de lingua portuguesa de outros países que se efetiva nos cursos de Letras teve pouco impacto sobre a formação do leitor, o que certamente tem consequências sobre a percepção de língua padrão e registros outros do português que não o brasileiro. O segundo é que autores e obras citados são todos das linguas mais conhecidas e culturalmente próximas do português, praticamente apenas dos idiomas da Europa Oriental, excluindo-se, por exemplo, a literatura eslava, a produção de países do Oriente Médio e da Ásia, conforme se verifica na Tabela 1, observando que a contagem é feita por aluno, mas um mesmo aluno pode se referir a mais de uma obra/autor.

Tabela 1 - Nacionalidade/língua

\begin{tabular}{|l|c|c|}
\hline \multicolumn{1}{|c|}{ Categoria } & Alunos & $\%$ \\
\hline Brasileira & 18 & 81,80 \\
\hline Inglesa & 6 & 27,30 \\
\hline Portuguesa & 3 & 13,60 \\
\hline Francesa & 3 & 13,60 \\
\hline Africana (LP) & 3 & 13,60 \\
\hline Latino-americana & 2 & 9,10 \\
\hline Alemã & 1 & 4,50 \\
\hline Espanhola & 1 & 4,50 \\
\hline
\end{tabular}

Fonte: Elaborada pelo autor.

O estatuto literário predominante das obras, conforme a Tabela 2, é o canônico, seguido com grande distância por obras de entretenimento, populares, didáticas (textos em antologia de livro didático ou obras paradidáticas) e religiosas. Aparentemente, apesar de citarem obras de estatuto diversificado, os alunos consideram que o contato com as obras canônicas é que realmente determina a formação do leitor ou assim avaliam porque acreditam que esta é a imagem que se espera de um leitor formado em Letras. 
Tabela 2 - Estatuto das obras

\begin{tabular}{|l|c|c|}
\hline \multicolumn{1}{|c|}{ Categoria } & Alunos & \% \\
\hline Canônico & 20 & 90,90 \\
\hline Entretenimento & 6 & 27,30 \\
\hline Popular & 5 & 22,70 \\
\hline Didático & 3 & 13,60 \\
\hline Religioso & 2 & 9,10 \\
\hline
\end{tabular}

Fonte: Elaborada pelo autor.

Essa análise é reforçada quando se verifica a distribuição do estatuto canônico entre blocos de endereçamento: infantil e adulto. Essa divisão considera que o sistema da literatura infantojuvenil possui um cânone próprio, embora receba forte influência do cânone adulto, sobretudo quando seus autores produzem obras endereçadas às crianças. Mais uma vez, o cânone nacional tradicional permanece como a grande referência para a definição de leitor entre os alunos, conforme a Tabela 3 .

Tabela 3 - Estatuto canônico das obras

\begin{tabular}{|l|c|c|}
\hline \multicolumn{1}{|c|}{ Categoria } & Alunos & \% \\
\hline Infantojuvenil & 7 & 31,80 \\
\hline Adulto & 20 & 90,90 \\
\hline
\end{tabular}

Fonte: Elaborada pelo autor.

Essa presença dominante do leitor adulto canônico é, ainda, ratificada de forma indireta quando se verifica o endereçamento das obras, independentemente de seu estatuto literário. Nesse caso, as obras direcionadas ao público adulto atingem $100 \%$ dos alunos, enquanto as infantis e juvenis não chegam nem à metade da turma, conforme a Tabela 4.

Tabela 4 - Endereçamento das obras citadas

\begin{tabular}{|l|c|c|}
\hline \multicolumn{1}{|c|}{ Categoria } & Alunos & \% \\
\hline Infantil & 9 & 40,90 \\
\hline Juvenil & 6 & 27,30 \\
\hline Adulto & 22 & 100,00 \\
\hline
\end{tabular}

Fonte: Elaborada pelo autor.

Em relação ao gênero, o romance se posiciona bem acima dos poemas e outros gêneros, conforme a Tabela 5, o que é compativel com o perfil geral dos leitores atuais, que leem mais narrativas do que poemas. Aqui, o que se destaca é, novamente, a pequena presença de gêneros que não ocupam o centro da chamada 
alta literatura, como a crônica e o cordel, embora se saiba que eles estão muito presentes nas escolas, quer como coletâneas para leitura extensiva, quer como textos de antologia dos livros didáticos. Também merece registro uma única referência a clássico adaptado, o que parece indicar que os alunos tendem a se considerar leitores a partir do acesso à literatura canônica adulta e não a partir da leitura dos textos direcionadas para as crianças, mesmo que esses possam ter prestígio cultural.

Tabela 5 - Gêneros das obras

\begin{tabular}{|l|c|c|}
\hline \multicolumn{1}{|c|}{ Categoria } & Alunos & $\%$ \\
\hline Romance & 16 & 72,70 \\
\hline Poema & 6 & 27,30 \\
\hline Conto & 5 & 22,70 \\
\hline Cordel & 2 & 9,10 \\
\hline Causo & 2 & 9,10 \\
\hline História em quadrinhos & 2 & 9,10 \\
\hline Crônica & 1 & 4,50 \\
\hline Outros & 1 & 4,50 \\
\hline Clássico adaptado & 1 & 4,50 \\
\hline Peça teatral & 1 & 4,50 \\
\hline
\end{tabular}

Fonte: Elaborada pelo autor.

Ainda dentro da categoria Obra, o período de publicação das obras citadas Tabela 6 - também ratifica a imagem de um leitor do cânone atualizado, dada a preferência por obras dos séculos XIX, XX e XXI. Também é digno de registro o número muito baixo de obras anteriores ao século XIX até a Antiguidade, o que indica, por um lado, que essas obras já não são tão frequentes na escola nem na leitura livre dos alunos; e, por outro, que a formação em Letras também não garante mais a leitura aprofundada dessas obras.

Tabela 6 - Época das obras citadas

\begin{tabular}{|l|c|c|}
\hline \multicolumn{1}{|c|}{ Categoria } & Alunos & $\%$ \\
\hline Século XX & 16 & 72,70 \\
\hline Século XXI & 9 & 40,90 \\
\hline Século XIX & 8 & 36,40 \\
\hline Século XV a XVIII & 2 & 9,10 \\
\hline Antiguidade & 1 & 4,50 \\
\hline
\end{tabular}

Fonte: Elaborada pelo autor. 
Na categoria Impacto, o período de vida em que se iniciou a formação de leitor literário e a preferência por um modo textual parecem seguir, à primeira vista, o que seria esperado no perfil de um leitor "padrão", ou seja, aquele que inicia a trajetória de leitor de obras literárias na infância e manifesta preferência por narrativas que claramente ocupam o centro do sistema literário. No caso do período de vida, os alunos indicam majoritariamente a infância (50\%), seguidos da maturidade $(27 \%)$ e adolescência (23\%). Já no caso do modo textual, as narrativas ficam com $68 \%$ de referências, ante os poemas, que não chegam a $10 \%$, sendo que os dois modos atingem 22\%. Todavia, quando relacionado com os dados já analisados acima, esse perfil se torna um tanto mais complexo. Em primeiro lugar, há que se considerar que o índice de mais de $25 \%$ da maturidade aponta para uma formação tardia de leitor literário, ou seja, um leitor literário que se forma em paralelo à formação profissional no curso de Letras. Depois, a baixíssima preferência por poemas, ao lado de uma baixa preferência por poemas e narrativas ao mesmo tempo, indica que a formação dada no curso de Letras funciona mais para constituir referências de leitura - daí a alta citação de autores e obras canônicas - do que constituir um leitor capaz de apreciar equilibradamente as duas formas mais básicas de manifestação literária em nossa cultura. Por fim, sugere que o perfil de um leitor do cânone delineado pela categoria Obra é muito mais uma imagem construída daquilo que os alunos imaginam ser um leitor ideal na área de Letras do que propriamente a realidade de suas preferências e práticas de leitura cotidianas.

Essas observações ganham maior consistência quando confrontadas com os indicadores da interação literária, conforme a Tabela 7. Embora os alunos apresentem quantitativos ao redor de $50 \%$ para os marcadores empatia e revelação, que são considerados índices de um leitor literário maduro, o marcador elaboração formal, que é mais relevante para o cânone tradicional, sobretudo a literatura produzida no século XX, não alcança a metade dos dois primeiros. Tal diferença indica um evidente descompasso com a imagem do leitor literário maduro e fortemente ligado às obras canônicas. Outro dado relevante é que os marcadores enredo e imersão, considerados como graus progressivos de interação literária e bastante comuns entre leitores iniciantes, não chegam a 50\%, mas os alunos que revelam ser a infância o momento decisivo de sua formação de leitor literária atingem 50\%. Ainda chama a atenção que o marcador empatia seja o mais destacado, o que mostra, por um lado, um alinhamento com a concepção de literatura defendida nos estudos culturais, e, por outro, uma tendência a se engajar com o texto literário mais por sua temática do que por sua linguagem.

Tabela 7 - Interação literária

\begin{tabular}{|l|c|c|}
\hline \multicolumn{1}{|c|}{ Categoria } & Alunos & \% \\
\hline Empatia & 12 & 54,50 \\
\hline Revelação & 11 & 50,00 \\
\hline Enredo & 9 & 40,90 \\
\hline Imersão & 6 & 27,30 \\
\hline Elaboração formal & 5 & 22,70 \\
\hline
\end{tabular}

Fonte: Elaborada pelo autor. 
A categoria Comportamento do Leitor, por fim, revela no indicador influência um forte impacto da escola na formação desses leitores literários que é bem superior à família, conforme se verifica na Tabela 8 . Também merece destaque a presença insignificante da influência de amigos, que aponta para uma relação basicamente vertical nas influências recebidas no processo de formação. Aparentemente, os compartilhamentos horizontais são irrelevantes ou pelo menos pouco considerados como determinantes para a formação do leitor, o que, somado à predominância da escola, pode indicar a necessidade de uma autoridade que apresente, incentive e sancione como válida a leitura de determinadas obras.

Tabela 8 - Influência na leitura

\begin{tabular}{|l|c|c|}
\hline \multicolumn{1}{|c|}{ Categoria } & Alunos & $\%$ \\
\hline Escola & 16 & 72,70 \\
\hline Família & 9 & 40,90 \\
\hline Outro & 3 & 13,60 \\
\hline Amigo & 1 & 4,50 \\
\hline
\end{tabular}

Fonte: Elaborada pelo autor.

Essa "autorização" que é parte da verticalidade fica mais evidente quando se desdobra a subcategoria escola em niveis de ensino. Dessa forma, como consta na Tabela 9, há uma simetria entre os três niveis, mostrando que a verticalidade atravessa igualmente todos os níveis de ensino, mesmo na graduação, quando supostamente os leitores teriam maior independência na seleção e compartilhamento dos textos.

Tabela 9 - Niveis de ensino

\begin{tabular}{|l|c|c|}
\hline \multicolumn{1}{|c|}{ Categoria } & Alunos & \% \\
\hline Ensino fundamental & 8 & 36,40 \\
\hline Ensino médio & 8 & 36,40 \\
\hline Graduação & 8 & 36,40 \\
\hline
\end{tabular}

Fonte: Elaborada pelo autor.

O último marcador parece contrariar um pouco esse destaque da escola ao revelar que o acesso aos textos se faz mais em casa do que no ambiente escolar, ao mesmo tempo que confirma a baixa horizontalidade, com o acesso via empréstimo entre amigos extremamente baixo. Essa aparente discrepância, porém, pode ser justificada tanto pela ausência de bibliotecas ou salas de leitura nas escolas quanto pelo fato de que as indicações de leitura escolares usualmente levam à aquisição individual da obra pelo aluno para a leitura em casa. Além disso, os textos também são objeto de presentes de familiares ou já fazem parte da biblioteca da família. 
Tabela 10 - Acesso aos textos

\begin{tabular}{|l|c|c|}
\hline \multicolumn{1}{|c|}{ Categoria } & Alunos & \% \\
\hline Casa & 9 & 40,90 \\
\hline Ambiente escolar & 6 & 27,30 \\
\hline Livraria & 4 & 18,20 \\
\hline Empréstimo de amigo & 1 & 4,50 \\
\hline
\end{tabular}

Fonte: Elaborada pelo autor.

Uma última observação sobre o acesso aos textos é a ausência de referência a biblioteca pública ou similar como espaço de aquisição de livros, assim como a referência pouco expressiva a livrarias quando uma parte dos leitores são adultos que se declaram influenciados pela universidade para a leitura das obras. Como não há outros dados sobre como se dá o acesso aos textos, sobretudo aqueles indicados pelos professores do curso de Letras, é possível supor que essa aquisição se faça por meio digital ou outra forma de reprodução que dispensa o livro como objeto impresso, entrando genericamente no marcador casa ou simplesmente não sendo referenciado pelos alunos porque é uma informação que não se destaca em seu cotidiano de leitor.

\section{Conclusão}

Enquanto prática de sala de aula, "O texto que me instituiu" não responde a todos os aspectos possiveis e desejados de um perfil de leitor literário. Na verdade, como sua ênfase é sobre a influência que determinados textos tiveram na formação do leitor, o texto resultante da prática pode minimizar ou mesmo deixar de lado dados relevantes sobre obras que foram lidas, mas que não permaneceram como marcos na memória do aluno. Do mesmo modo, o registro feito pelo aluno do texto ou textos que o instituíram pode restringir o impacto da leitura literária e o comportamento leitor ao que aconteceu na interação com esses textos capitais, passando ao largo de práticas de leitura mais cotidianas e corriqueiras de textos literários. Tais limitações podem, ainda, levar o aluno a não se reconhecer no perfil delineado individualmente e até como turma.

Todavia, há vários beneficios em se adotar a prática como uma forma de delinear um perfil de leitor. Em primeiro lugar, embora sejam comuns a vários perfis de leitores traçados com outros instrumentos, as categorias são construídas a posteriori, ou seja, após a leitura dos textos produzidos pelos alunos. Não se trata, portanto, de aplicar uma lista prévia e fechada de categorias e indicadores aos textos, mas sim de reconhecer nas memórias a presença de determinadas categorias. Esse procedimento pode deixar de fora informações que teoricamente são importantes, como hábitos de leitura e autoimagem de leitor, mas tem a vantagem de verificar o que é significativo e específico para aqueles alunos enquanto se instituem como leitores.

Depois, como as categorias não são fixas como em um questionário nem se repetem as informações presentes nos textos dos alunos, ao contrário, elas se alteram de turma para turma, há uma necessidade permanente de adaptação 
dos marcadores e da análise por parte do professor. Tal exigência não só favorece a indicação de textos e planejamento de atividades mais direcionados para aquela turma, como também imprime ao delineamento do perfil de leitor um cunho dinâmico que a rotina de aplicação e tabulação automática de questionários não tem como oferecer.

Por fim, para além do conjunto de dados que podem ser depreendidos dos textos dos alunos, a prática da leitura, discussão e escrita da memória de leitor traz para a primeira aula um ambiente de compartilhamento de leituras que é de grande importância quando se ensina literatura. Nessa prática interativa que dá início a um curso, professor e alunos reconhecem uns aos outros e se autoconhecem como leitores em um processo permanente de construção de seu corpo linguagem, de uma comunidade de leitores, o processo do letramento literário, enfim.

\section{“MADE IN THE TEXT": AN ALTERNATIVE READER'S PROFILE}

Abstract: The traditional way to chart a reader's profile is to survey the reading behavior of a target population. In this paper, we introduce the pedagogical practice of "Made in the text" as an alternative to this usual way to chart the reader's profile. The data come from Language graduate students, and we used the software QDA Miner to support the content analysis. The results show that the practice is a suitable way to chart the reader's profile of students since high school. It is very useful not only for planning future readings as well as to improve the interaction between the students e the teacher from the first day of class.

Keywords: Reader's profile. Reader's history. Pedagogic practice. Literary literacy. Literary reader.

\section{REFERÊNCIAS}

ALMEIDA, N. K. L. de J. Memória e formação de professores leitores: imaginário, subjetividades e afetividades literárias. 2019. Dissertação (Mestrado em Ensino na Educação Básica) - Universidade Federal de Goiás, Goiânia, 2019. Disponivel em: http://repositorio.bc.ufg.br/tede/handle/tede/10073. Acesso em: 10 set. 2020.

AMARAL, J. Biblioteca e leitura em retratos: percepções sobre o ensino técnico. Revista Leia Escola, v. 18, n. 2, p. 9-19, nov. 2018. Disponivel em: http://revistas. ufcg.edu.br/ch/index.php/Leia/article/view/1110. Acesso em: 8 abr. 2020.

ASSOLINI, F. E. P. Leitura e formação inicial de professores: sentidos, memória e história a partir da perspectiva discursiva. Pro-Posições, v. 22, n. 1, p. 33-43, abr. 2011. Disponivel em: http://www.scielo.br/scielo.php?script=sci_arttext\& pid=S0103-73072011000100004\&lng=en\&nrm=iso. Acesso em: 10 mar. 2019.

CHUCRE, M. do S. de J. Leitura e leitores: um perfil de alunos do ensino fundamental II em uma escola pública de Campinas - SP. 2018. Dissertação (Mestrado Profissional em Letras em Rede) - Universidade de São Paulo, São Paulo, 2018.

COSSON, R. Letramento literário: teoria e prática. São Paulo: Contexto, 2006. 
DRESCH, M. et al. Memórias de leitura, lugar de leitor e conhecimento na formação inicial de docentes. Pro-Posições, v. 22, n. 1, p. 45-58, abr. 2011. Disponivel em: http://www.scielo.br/scielo.php?script=sci_arttext\&pid=S0103-73072 011000100005\&lng=en\&nrm=iso. Acesso em: 15 mar. 2019.

FAILLA, Z. (org.). Retratos da leitura no Brasil 4. Rio de Janeiro: Sextante, 2016. FARIAS, F. R. O leitor e a leitura revelados pela Retratos da leitura no Brasil: uma análise à luz da teoria da semicultura. 2018. Tese (Doutorado em Educação) - Universidade Federal de Minas Gerais, Belo Horizonte, 2018. Disponível em: http:/ / hdl.handle.net/1843/BUOS-B69FFJ. Acesso em: 10 jan. 2020.

GIROTTO, C. G. G. S.; FRANCO, S. A. P. (org.). Perfil do leitor universitário: textos e contextos nas licenciaturas. Tubarão, SC: Copiart, 2017.

MASOOMI, M.; ZARGAR, S. The effects of writing literary response paper on different aspects of students' attitudes toward literature. International Journal of English and Education, v. 6, n. 1, Jan. 2017. Disponivel em: http://www.ijee. org/yahoo_site_admin/assets/docs/25.8123327.pdf. Acesso em: 10 mar. 2020.

MIALL, D.; KUIKEN, D. Aspects of literary response: a new questionnaire. Research in the Teaching of English, v. 29, p. 37-58, 1995. Disponivel em: https://sites.ualberta.ca/ dmiall/MiallPub/Miall_Kuiken_LRQ_95.htm. Acesso em: 15 mar. 2020.

MONAK, L. Metodologia comum para examinar e medir o comportamento leitor. O encontro com o digital. Bogotá: Cerlac-Unesco, 2015. Disponivel em: https:// cerlalc.org/pt-br/publicaciones / ptmetodologia-comum-para-examinar-e-mediro-comportamento-leitor-o-encontro-com-o-digital/. Acesso em: 15 mar. 2020.

ORGANIZAÇÃO PARA A COOPERAÇÃO E DESENVOLVIMENTO ECONÔMICO - OCDE. Programme for International Student Assessment 2009. Questionário de Contexto. Questionário do Aluno. Portugal. Disponível em: https://iave.pt/ estudo-internacional/pisa/. Acesso em: 10 mar. 2020.

PAGNAN, C. L. et al. A prática da leitura: hábitos e suportes. Nuances: Estudos sobre Educação, v. 29, n. 2, p. 139-155, maio/ago. 2018. Disponível em: https://revista.fct.unesp.br/index.php/Nuances/article/view/5103. Acesso em: 10 mar. 2020.

SCHOOTEN, E. van et al. Dimensions and predictors of literary response. Journal of Literacy Research, v. 33, n. 1, p. 1-32, 2001. Disponivel em: https://doi.org/ 10.1080/10862960109548101. Acesso em: 15 mar. 2020.

WONG, M. L. S. L. Meaning-making strategies in the literary reading of gifted secondary two students in Singapore. 1997. Institute Thesis (Master of Education) - Nanyang Technological University, Singapore, 1997. Disponivel em: https:/ / repository.nie.edu.sg/bitstream/10497/1181/3/WongMarieLindaShiu Leung-MED.htm. Acesso em: 15 mar. 2020.

YUBERO, S. et al. Estudo sobre os hábitos de leitura dos estudantes portugueses do ensino superior. Cuenca: Cepli/Castelo Branco, IPCB, 2014. Disponível em: ttp://hdl.handle.net/10400.11/2454. Acesso em: 15 mar. 2020. 